\title{
Whoever is Influential is Successful too: How Chinese Undergraduates Choose Admirable People in Chinese Societies
}

Xiao Dong Yue ${ }^{*}$ and Neelam Arjan Hiranandani

Department of Applied Social Studies, City University of Hong Kong, 81 Chee Avenue. Kowloon Tong Hong Kong SAR China

\section{Abstract}

This study examined how meritorious evaluation bias (MEB) played a role in determining how Chinese Hong Kong students and Guangzhou nominated the most successful and the most likeable people. Results showed that when choosing the most successful people, students from both cities nominated mostly politicians and scientists; when choosing the most likeable people, students from both cities nominated mostly politicians and pop-movie stars. Rarely did students in either city nominated artists, musicians, and businessmen. These findings validated the meritorious evaluation bias (MEB) discovered by the author about the nomination of admirable people in Chinese society, such as, the more social merits, contribution or influence a person has, the higher, he or she is likely to be accorded with.

\section{Publication History:}

Received: July 26, 2016

Accepted: October 10, 2016

Published: October 12, 2016

\section{Keywords:}

Creativity, Chinese, Meritorious Evaluation bias

\section{Introduction}

People's judgment of attributional characteristics is based on the standards existing in the social and cultural milieu [1,2]. Crosscultural studies show that the Chinese perception of creativity differs fundamentally from that in the West in that the former is based on an overarching concern for others, which emphasizes the meritorious salience of creativity, while the latter is focused on the individual, and emphasizes the aesthetic salience of creativity [3-8]. As such, the Western perception of creativity is typically oriented towards having freedom of expression, striving for independence, and enhancing novelty in thinking $[8,13]$. In contrast, the Chinese perception of creativity is oriented towards fulfilling one's social obligations [8, 14-16] and embracing strong ethical and instrumental standards [17-21]. To account for this cultural difference, it is emphasized in Confucianism, that "rendering meritorious service typically involves helping those in distress, ridding the world of evil, and benefiting the world in general by good works" [22]. Thus, most Chinese intellectuals value establishing meritorious service as a top achievement above all others [23]. The role of intellectuals is not only to express or manifest oneself in the society, but also to develop an internal moral self and to make an altruistic dedication to society, which exactly fits the Confucian principle of 'conquering selfishness to restore ritual propriety' [22].

In line with the above arguments, [7] proposed that Chinese people were inclined to define creativity in terms of a meritorious evaluation bias (MEB), such that the more social merits or influence a person has, the higher creativity he or she is likely to be accorded with Alternatively, meritorious salience of a person's creativity would evoke positive expectations of his or her creative deeds $[7,8]$.

To test the MEB, Yue conducted two related studies. In study one, [7] asked 194 Hong Kong undergraduates and 220 Guangzhou undergraduates to nominate up to three of the most creative Chinese people they would think of, and subsequently rate these regarding their level of creativity and social contribution to society. The study showed that scientists, inventors, and politicians were nominated most frequently, whereas artists, musicians and entertainers were rarely nominated. In addition, scientists, inventors, politicians, and educators were rated significantly higher on social contribution than on creativity whereas writers, poets, and artists were rated significantly higher on creativity than on social contribution. These findings offer strong support for the hypothesized MEB in the Chinese perception of creativity: those who distinguish themselves in meritorious salience of creativity are considered as more prototypical of creativity in Chinese societies than those who distinguish themselves in aesthetic salience of creativity.

In study two, [8] broadened the samples to encompass five major cities in China, and asked participants to rate the level of creativity and social contribution of those twenty Chinese individuals identified in the first study [7]. The results showed again that scientists, inventors, politicians, and educators were rated significantly higher on social contribution than on creativity, whereas writers, poets were rated significantly higher on creativity that on social contribution. Additionally, both studies suggested that Guangzhou Chinese students were more influenced by the MEB than their counterparts in Hong Kong.

This present study uses a similar framework in which, it aims to prove that Chinese people would be inclined to define or attribute success or likeable in terms of a meritorious evaluation bias (MEB), which means, the more social merits / social contribution / social influence one has, the more successful and likeable he is likely to be. It is interesting to examine if the MEB would apply to choice of admirable people to young people in Chinese societies. If so, it would offer stronger support to the proposed cultural effect of Chinese perception of creativity. Thus conceived, the present study is a follow-up study to investigate how people nominate most successful people based on their social contribution to society. This study aims to examine (1) how Chinese young people would nominate the most successful Chinese people they could think of and, (2) how these people would be rated on their levels of success as compared with that for their social contribution to society. Therefore, this study hypothesized that (H1): Nomination of the most successful Chinese would be influenced by the MEB, such that, the more social contribution or social influence

"Corresponding Author: Prof. Xiao Dong Yue, Department of Applied Social Studies, City University of Hong Kong, 81 Chee Avenue. Kowloon Tong Hong Kong SAR China; E-mail: ssxdyue@cityu.edu.hk

Citation: Yue XD, Hiranandani NA (2016) Whoever is Influential is Successfu too: How Chinese Undergraduates Choose Admirable People in Chinese Societies. Int J Psychol Behav Anal 2: 115. doi: http://dx.doi.org/10.15344/2455$3867 / 2016 / 115$

Copyright: (c) 2016 Yue. This is an open-access article distributed under the terms of the Creative Commons Attribution License, which permits unrestricted use, distribution, and reproduction in any medium, provided the original author and source are credited. 
Citation: Yue XD, Hiranandani NA (2016) Whoever is Influential is Successful too: How Chinese Undergraduates Choose Admirable People in Chinese Societies. Int J Psychol Behav Anal 2: 115. doi: http://dx.doi.org/10.15344/2455-3867/2016/115

Page 2 of 4

a person had, the more likely he or she would be nominated and the higher successfulness he or she would be likely to be accorded and vice versa; (H2) Mainland young people would be more subject to the influence of MEB when nominating the most successful Chinese than did their counterparts in Hong Kong.

\section{Method}

\section{Participants}

A total of 909 students were sampled to participate in this study, including 79 undergraduates and 68 high school students from Hong Kong, and 386 undergraduates and 376 high school students from Guangzhou. The average age for the Hong Kong sample was 20.4 years $(\mathrm{SD}=1.7)$ for undergraduates and 15.2 years $(\mathrm{SD}=2.4)$ for high school students, the average age for the Guangzhou sample was 20.0 years $(\mathrm{SD}=2.6)$ for undergraduates and 15.3 years $(\mathrm{SD}=1.3)$ for high school students. The universities and high schools being sampled were generally comparable in their size and prestige.

\section{Measures}

This study is a follow-up study on Yue's previous papers. This study collects qualitative data and it uses the similar measures and procedures to analyze data. Participants were asked to complete a specifically designed questionnaire for this study. Participants were asked to: (1) nominate up to three of the most successful Chinese people they know of in Chinese history or in modern times, including overseas Chinese, to (2) specify briefly the reasons for nominating these Chinese people, and to (3) rate on a 10-point Likert scale $(1=$ least, $10=$ most) each of these nominees' degree of success and social contribution $[7,8]$. The questionnaires were printed in simplified Chinese characters for respondents in China, and in traditional Chinese characters for respondents in Hong Kong.

To avoid a possible familiarity effect in nomination, all respondents were required to specify their reasons for nomination. Thus, the chances that respondents would nominate people just because their names sounded familiar or were famous were minimized [3, 7]. The term "social contribution" (shehui gongxian) was used instead of other likely terms such as "social influence"(shehui yingxiang), "social recognition"(shehui renshi), or "social significance" (shehui yiyi), based on the assumption that "social contribution" captured best the meaning of social merits of creativity as reflected in the hypothesized meritorious evaluation bias $[7,21]$.

\section{Procedures}

Participants were told that the goal of the study was to obtain information about how successful and likeable people were perceived and judged in Chinese societies. There was no time limit for completing the questionnaire. On average, participants took 20 minutes to complete the questionnaire. The questionnaires were administered in group sessions during lecture or tutorial time.

To code all the nominated successful and likeable Chinese, a three-step procedure was employed $[3,7,8]$. In step one, two separate master lists of nominations were compiled with one list containing all historical figures, and the other one all modern figures. In step two, two independent coders (the author and a research assistant) assigned a category of achievement to each nominee. The categorization was based on the major area of activity or achievement the given nominee was best known for. If a nominee was active in a number of domains or roles, the person would be coded for what he or she was most known, as agreed on by the two coders. In addition, as the last feudal dynasty ended in China around the turn of the 20th century, a cut-off line was set up to distinguish nominees in Chinese history from those in modern times. Specifically, those who died before 1900 were all coded as historical figures, those who died after 1900 or are still alive at the time of the study were coded as modern figures.

For statistical purposes, all of the nominees were grouped into ten broad occupational categories in step three, following the coding procedure by Yue and [3], which included scientists/inventors, politicians, writers/ poets, philosophers/educators, artists, musicians, generals/military strategists, businessmen, pop-stars. Those nominees who had no social influence or recognition, e.g., family members, relatives, teachers, or people totally unknown to the two coders, or were very special in their own ways, e.g., Godly figures, cartoon figures, or fictional figures, were all placed under the category of "others".

\section{Results}

Table 1 displays percentages of nomination of the most successful Chinese by all students. As predicted, nomination of politicians was highly prevalent in all samples. Specifically, politicians accounted for $44.0 \%$ and $46.7 \%$ of all nominations for Hong Kong high school and university students, respectively, and $44.6 \%$ and $60.4 \%$ of all nominations for the Guangzhou high school and university students, respectively. In contrast, artists/musicians, pop stars/movie stars and sports stars only accounted for $15.0 \%$ and $10.8 \%$ of all nominations for Hong Kong high school and university students, respectively, and $7.6 \%$ and $3.1 \%$ of all nominations for the Guangzhou high school and university students, respectively.

\begin{tabular}{|l|l|l|l|l|}
\hline Nominees & $\begin{array}{l}\text { HK HS } \\
\text { students } \\
(n=68)\end{array}$ & $\begin{array}{l}\text { HK under- } \\
\text { graduates } \\
(n=79)\end{array}$ & $\begin{array}{l}\text { GZ HS } \\
\text { students } \\
(n=376)\end{array}$ & $\begin{array}{l}\text { GZ under- } \\
\text { graduates } \\
(n=386)\end{array}$ \\
\hline Scientists/Inventors & 4.74 & 8.59 & 16.90 & 8.67 \\
\hline Politicians & 44.01 & 46.70 & 44.60 & 60.40 \\
\hline Writers/Poets & 8.08 & 11.45 & 14.33 & 12.26 \\
\hline $\begin{array}{l}\text { Philosophers/ } \\
\text { Educators }\end{array}$ & 5.01 & 8.15 & 7.69 & 6.38 \\
\hline Artists/Musicians & 2.23 & 1.32 & 2.11 & 0.72 \\
\hline $\begin{array}{l}\text { Generals/Military } \\
\text { Strategists }\end{array}$ & 8.64 & 5.73 & 2.43 & 2.96 \\
\hline Businessmen & 3.34 & 6.17 & 4.35 & 4.58 \\
\hline $\begin{array}{l}\text { Pop Stars/Movies } \\
\text { Stars }\end{array}$ & 11.70 & 7.05 & 4.85 & 1.53 \\
\hline Sports Stars & 1.11 & 2.42 & 0.60 & 0.85 \\
\hline Heroes & 0.56 & 0.44 & 0.87 & 0.36 \\
\hline Others & 0.28 & 0.66 & 0.78 & 0.58 \\
\hline Non-celebrities & 9.19 & 0.22 & 0.23 & 0.27 \\
\hline Unknown & 1.11 & 1.10 & 0.27 & 0.45 \\
\hline
\end{tabular}

Table 1: Percentage of the Most Successful Chinese Nominated by All Students.

Note: $\mathrm{HS}=$ High school students; GZ = Guangzhou

In addition, nomination of politicians by the Guangzhou university students substantially outnumbered that by the Hong Kong university students $(60.4 \%: 46.7 \%)$; similarly, nomination of scientists/inventors by the Guangzhou high school students' outnumbered substantially that by the Hong Kong high school students (16.9\%: $4.7 \%)$ It is intriguing to note that nominations of scientists/inventors were all within single digits except for the Guangzhou high school students (16.9\%). 
Citation: Yue XD, Hiranandani NA (2016) Whoever is Influential is Successful too: How Chinese Undergraduates Choose Admirable People in Chinese Societies. Int J Psychol Behav Anal 2: 115. doi: http://dx.doi.org/10.15344/2455-3867/2016/115

Page 3 of 4

Table 2 displays the mean scores of success (SU) and social contribution (SC) for the ten groups of nominees. The SC mean scores were significantly higher than SU mean scores for scientists/inventors $(t=-2.00, p<0.5)$ and philosophers/educators for the Hong Kong sample. The SU mean scores were consistently higher than the SC mean scores for artists/musicians, writers/poets, businessmen, pop/ movie stars, and sports stars in all samples. The mean differences for $\mathrm{SU}$ and SC ratings for pop/ movies stars were statistically significant for both samples (Guangzhou: $t=7.71 ; p<.001$; Hong Kong: $t=2.68$; $p<.01)$, whereas mean differences for businessmen were statistically significant for the Hong Kong sample $(t=2.87, \mathrm{p}<.01)$, and the mean differences for artists/musicians $(t=3.91, p<.0 .001)$, and sports stars $(t=4.82 p<.001)$ were statistically significant for the Guangzhou sample.

\begin{tabular}{|l|l|l|l|l|l|l|}
\hline & \multicolumn{3}{|l|}{$\begin{array}{l}\text { Guangzhou Students } \\
(n=762)\end{array}$} & \multicolumn{3}{l|}{$\begin{array}{l}\text { Hong Kong Students } \\
(n=147)\end{array}$} \\
\hline & SU & SC & $t$-value & SU & SC & $t$-value \\
\hline $\begin{array}{l}\text { Scientists/ } \\
\text { Inventors }\end{array}$ & 8.93 & 8.93 & .30 & 8.64 & 9.09 & $-2.00^{*}$ \\
\hline Politicians & 9.01 & 8.75 & $9.42^{* * *}$ & 8.59 & 8.23 & $3.80^{* * *}$ \\
\hline Writers/ Poets & 8.55 & 8.00 & $8.99^{* * *}$ & 8.27 & 7.51 & $3.29^{* * *}$ \\
\hline $\begin{array}{l}\text { Philosophers/ } \\
\text { Educators }\end{array}$ & 8.79 & 8.41 & $3.54^{* * *}$ & 8.11 & 8.53 & -1.48 \\
\hline Artists/ Musicians & 8.70 & 7.52 & $3.91^{* * *}$ & 8.27 & 7.13 & 1.79 \\
\hline $\begin{array}{l}\text { Generals/ } \\
\text { Military } \\
\text { Strategists }\end{array}$ & 8.39 & 8.17 & .945 & 8.08 & 7.21 & $2.29^{*}$ \\
\hline Businessmen & 9.11 & 8.26 & $7.77^{* * *}$ & 8.26 & 7.31 & $2.87^{* *}$ \\
\hline $\begin{array}{l}\text { Pop Stars/ Movies } \\
\text { Stars }\end{array}$ & 8.82 & 7.35 & $7.71^{* * *}$ & 8.19 & 7.38 & $2.68^{* *}$ \\
\hline Sports Stars & 8.96 & 7.04 & $4.82^{* * *}$ & 7.92 & 6.17 & $4.47^{* * *}$ \\
\hline Heroes & 8.70 & 8.36 & 1.37 & 8.58 & 8.56 & .122 \\
\hline
\end{tabular}

Table 2: Scores of Success and Social Contribution of the Most Successful Chinese Nominated by All Students

Note: $\mathrm{SU}=$ Degree of Success; $\mathrm{SC}=$ Social Contribution

${ }^{\star} \mathrm{p}<.05,{ }^{* *} \mathrm{p}<.01,{ }^{* * *} \mathrm{p}<.001$

Taken together, the above findings confirmed that politicians and scientists/inventors, who usually distinguish themselves in meritorious salience, were recorded higher SC scores than SU scores, offering support to hypothesis 1, whereas artists/musicians, who usually distinguish themselves in aesthetic salience, were recorded higher SU scores than SC scores $[7,8]$. This may be attributed to the fact that Chinese moral education advocated many writers/poets as role models of self development for school children [8]. Taken together, the present findings offer little support to Hypothesis 2 but show some additional regional difference, i.e., in nominating the most lively people, Hong Kong students chose more pop/movie stars whereas the Guangzhou students chose more writers/poets as admirable people of life.

\section{Discussion}

This study attempts to examine the existence of the meritorious evaluation bias (MEB) in Chinese young people's view of admirable people. The term of "admirable people" is hereby defined as those who are worthy of young people's special favor, respect, and identification [24]. The Western notion of amicability is generally characterized by having elegance, simplicity [25], and embedded beauty [26], in contrast, the Chinese notion of amicability is generally featured by having personal virtues, successes and social significance [7]. While nominating the most successful, high school and university Hong Kong students mostly nominated politicians, followed by pop/movie stars, writers/poets, whereas high school and university Guangzhou students mostly nominated politicians, followed by writers/poets and pop/movie stars. Rarely did students in either area nominate artists, musicians, and businessmen. These findings confirm the previous findings that those who distinguish themselves in meritorious salience are more likely to be perceived as successful and likeable than those who distinguish themselves in aesthetic salience. Alternatively, whoever is influential is successful and likeable as well.

MEB is an attributional bias in perceiving the admirable people to Chinese young people, and MEB also enables us to re-examine the old research paradigms beyond the motivational, dispositional and perceptual characteristics of the significant other to Chinese young people. For instance, research studies show that the Western notion of success places a heavy emphasis on such personal factors as ability, effort, task difficulty, and luck $[27,28]$. In school settings, personal success is associated with leadership, athletics, academics, popularity, humor and musicianship [29,30]. In Chinese society, however, the notion of success is characterized by its social aspects, such as social influence, social recognition, and social contribution [31]. In other words, personal success has to be substantiated by social contribution in Chinese culture. That Chinese young people in both Hong Kong and Guangzhou mostly nominated politicians offers strong support for the effect of a MEB in choosing admirable people by Chinese young people.

It is intriguing to note that Hong Kong students placed more value on pop/movie stars while Guangzhou students place more value on writers/poets. This may largely be attributed to the different foci in moral education [8]. Specifically, civic education in Hong Kong emphasizes the importance of becoming a good citizen while moral education in China stresses the importance of serving the society. In addition, young people in Hong Kong typically look up to pop stars, movie stars, and star stars as their idols of life [16, 32], and this has become an increasingly market-driven via mass media and entertainment industries [32,33]. So, for Hong Kong young people, personal success and likeableness is largely related to personal glamour, wealth, charisma, and hedonism [32]. In China, however, young people have been used to idolizing statesmen, heroes, public role models, and accomplished scholars [32]. Moreover, Chinese moral education is largely featured by promoting various well-known Chinese or foreign luminaries as role models of identity formation and self-determination [34]. As a result, Guangzhou young people tend to embrace these people as role models of personal successes and aspirations. Interestingly, the author's recent studies on perception of humorist followed the same pattern that Chinese students nominated significantly more politicians and writers as humorists than their counterparts in Hong Kong [35].

It should be cautioned that the present samples are only confined to undergraduates and high school Guangzhou students. The sampled young people are far from being representative of the diverse populations in Chinese societies. A larger and more diverse sample in future studies is clearly needed to address the generalizability of the present findings. Therefore, it would be interesting to examine how young people living in the rural areas of China view success and likeableness as compared with those living in urban areas. It would 
Citation: Yue XD, Hiranandani NA (2016) Whoever is Influential is Successful too: How Chinese Undergraduates Choose Admirable People in Chinese Societies. Int J Psychol Behav Anal 2: 115. doi: http://dx.doi.org/10.15344/2455-3867/2016/115

also be necessary to include young people of various age, education background and occupational characteristics.

\section{Conclusion}

In conclusion, this study breaks ground in examining how young people from Hong Kong and Guangzhou perceive the attributional characteristics of admirable people. Findings indicate that a MEB not only applies to young people' choice of the most creative people in Chinese society, but also to their choice of the most successful and most likeable people in Chinese society. This finding sheds new light on not only studying the cultural effect of perceiving and attributing admirable people in Chinese societies but also on helping young people to view admirable people in more diverse and self-enhancing ways.

\section{Competing Interests}

The authors declare that they have no competing interests.

\section{Funding}

This research was funded by a grant from the City University of Hong Kong (Grant No. 7004315).

\section{References}

1. Csikszentmihalyi M (1988) Society, culture, and person: a system view of creativity. In Sternberg RJ (Ed.) The nature of creativity. New York: Cambridge University Press 325-339pp

2. Ludwig AM (1992) Culture and creativity. Ame J Psychother 46: 454-469

3. Hsu FLK (1981) Americans and Chinese: Passage to differences. (3rd ed) Honolulu HI: University of Hawaii Press.

4. Sternberg RJ (1985) Implicit theories of intelligence, creativity, and wisdom J Personal Social Psychol 49: 607-627.

5. Yue XD, Rudowicz E (2002) Perception of the most creative Chinese by undergraduates in Beijing, Guangzhou, Hong Kong and Taipei. J Creative Behav 36: 88-104.

6. Rudowicz E (2003) Creativity and culture: A two way interaction. Scandinav J Edu Res 47: 273-290.

7. Yue XD (2003) Meritorious attribution bias: How Chinese undergraduates perceive Chinese and foreign creators. J Creative Behav 37: 151-178.

8. Yue XD (2004) Whoever is influential is creative: How Chinese undergraduates choose creative people in Chinese societies. Psychol Report 94: 1235-1249.

9. Runco MA, Bahleda MD (1987) Implicit theories of artistic, scientific and everyday creativity. The J Creative Behav 20: 93-98.

10. Amabile TM (1996) Creativity in context: Update to The Social Psychology of Creativity. Oxford: Westview Press.

11. Mayer RE (1999) Fifty years of creativity research. In Sternberg RJ (Ed) Handbook of creativity. New York: Cambridge University Press 449-460.

12. Sternberg RJ, Lubart TI (1999) The concept of creativity: Prospects and paradigms. In Sternberg RJ (Ed.), Handbook of creativity. New York: Cambridge University Press. 3-15.

13. Ng AK (2001) Why Asians are less creative than Westerners. Singapore Prentice Hall.

14. Yue XD, Bender M, Cheung CK (2011) Who are the best known national and foreign creators-a comparative study among undergraduates in China and Germany. J Creative Behav 45: 23-37.

15. Yue XD, Leung K (2003) Motives and attitudes for creativity: Views from undergraduates in Hong Kong and Guangzhou. New Horizon Edu 47: 1-5. [in Chinese]
16. Yue XD, Cheung KC (2000) Selection of favorite idols and models among Chinese young people: A comparative study in Hong Kong and Nanjing. Int J Behav Develop 24: 91-98.

17. Wu WT (1996) Many faces of creativity. In Cho S, Moon JH, Park JO (Eds.) Selected Proceedings of the 3rd Asia-Pacific Conference on Giftedness. Korea 123-128 pp.

18. Chan J (1997) Creativity in the Chinese culture. In Chan J, Li R, Spinks $\mathrm{J}$ (Eds.), Maximizing potential: Lengthening and strengthening our stride. Proceedings of the 11th World Conference on Gifted and Talented Children. Hong Kong: The University of Hong Kong, Social Sciences Research Centre. 212-218.

19. Wang DD, Duan $X Q$, You $L$ (1997) Creative education: On way toward training creative talents for the 21st century. In Chan J, Li R, Spinks J (Eds.), Maximizing potential: lengthening and strengthening our stride. Proceed 11th World Conf Gifted Talented Child Hong Kong: The University of Hong Kong, Social Sciences Research Centre 689-690 Pp.

20. Shi J, Zha Z (2000) Psychological research on and education of gifted and talented children in China. In Heller KA, Monks FJ, Sternberg RJ, Subotnik RF (Eds.), Int Handbook Res Giftedness Talent. Amsterdam: Elsevier Press 757-764

21. Yue XD, Ho KK (2002) A study of the meritorious evaluation bias among Hong Kong primary and secondary school teachers in the selection of creative Chinese individuals. New Horizons in Edu 45: 28-33. [in Chinese]

22. Yu AB (1996) Ultimate life concerns, self and Chinese achievement motivation. In Bond MH (Ed.), The Handbook of Chinese Psychology. Hong Kong: Oxford University Press 208-226 pp.

23. Wen Cl (1989) Chinese Values. Taipei: The Grand-East Book Co.

24. Woefel J, Haller A (1971) Admirable people, the self-reflexive act and the attitude formation process. Ame Sociol Rev 36: 74-87.

25. Lipton P (2004) Inference to the best explanation. New York: Routledge.

26. Ross EA (1919) Social psychology: An outline and source book. New York Macmillan Co 94-109.

27. Weiner B (1974) Achievement motivation and attribution theory. Morristown $\mathrm{NJ}$ : General Learning Press.

28. Weiner B (1986) An attributional theory of motivation and emotion. New York: Springer-Verlag.

29. Quatman T, Sokolik E, Smith K (2000) Adolescent perception of pee success: A gendered perspective over time. Sex Roles 43: 61-84.

30. Meulemann $\mathrm{H}$ (2001) Life satisfaction from late adolescence to mid-life: The impact of life success and success evaluation on the life satisfaction of former gymnasium students between ages 30 and 43 . J Happiness Stud 2: $445-465$

31. Lu L (2001) Understanding happiness: A look into the Chinese folk psychology. J Happiness Stud 2: 407-32.

32. Cheung CK, Yue XD (2000) Idol worshipping for vain glory, illusory romance or intellectual learning: a study in Nanjing and Hong Kong. Int $J$ Adolescence Youth 8: 299-317.

33. Wan MP (1997) Constructing love relationship with idols. Hong Kong Anthropol 10: 25-31.

34. Cheung C, Yue XD (2007) Which Chinese creators are famous and why Views from Hong Kong and Mainland Chinese students. J Creative Behav 41: 177.

35. Yue XD, Hiranandani NA (2014) Perception of humorists: a cross-cultural study of undergraduates in Hong Kong, Hangzhou, and Vancouver Comprehens Psychol 3: 07-17. 